\title{
Validation of computer software to estimate dietary intake among patients with type 2 diabetes
}

\author{
Sayori Wada, ${ }^{1, *}$ Eru Yamamoto, ${ }^{2}$ Yukiko Kobayashi, ${ }^{1}$ Manami Otsuki, ${ }^{3}$ Chizuko Takada, ${ }^{3}$ Wataru Aoi, ${ }^{1}$ \\ Masami Okagaki, ${ }^{3}$ Hiroko Neriya, ${ }^{3}$ Masahide Hamaguchi, ${ }^{4}$ Muhei Tanaka, ${ }^{4}$ Michiaki Fukui, ${ }^{4}$ and Akane Higashi ${ }^{1}$ \\ ${ }^{1}$ Division of Applied Life Sciences, Graduate School of Life and Environmental Sciences and ${ }^{2}$ Department of Food Sciences and Nutritional Health, \\ Faculty of Life and Environmental Sciences, Kyoto Prefectural University, 1-5 Shimogamo, Hangi-cho, Sakyo-ku, Kyoto 606-8522, Japan \\ ${ }^{3}$ Department of Clinical Nutrition, University Hospital, Kyoto Prefectural University of Medicine and ${ }^{4}$ Department of Endocrinology and Metabolism, \\ Kyoto Prefectural University of Medicine Graduate School of Medical Science, Kajii-cho, Kawaramachi-Hirokoji, Kamigyo-ku, Kyoto 602-8566, Japan
}

(Received 9 April, 2020; Accepted 1 August, 2020; Published online 21 October, 2020)

Tailored nutritional guidance by a registered dietitian is necessary for feasible, practical application of nutrition therapy. In order to reduce the requirement for estimation by a dietitian and to increase the time available for practical advice, we developed and validated computer software for estimating dietary intake among patients with type 2 diabetes. The study enrolled 46 patients with type 2 diabetes, recruited from an outpatient clinic in 2015. We used the computer software "Syokuseikatsu Shindan System" (SSS; Nissha, Kyoto, Japan). SSS allows the user to choose pictures of dishes and the portions he/she has consumed for each meal. The one-day dietary intake estimations for SSS were validated against a reference estimation of 24-h dietary recall by a registered dietitian. The mean carbohydrate intake as assessed by SSS and 24-h recall was $210.6 \pm 55.1$ and $215.5 \pm 52.9 \mathrm{~g} /$ day, with a positive correlation $(r=0.53, p<0.001)$. Bland-Altman analysis showed that limits of agreement in carbohydrates between the methods were -107.4 to $97.5 \mathrm{~g} /$ day. Even though the limits of agreement were wide and non-negligible at the individual level for clinical use, SSS appears to have potential as a dietary estimation tool under registered dietitian supervision.

Key Words: dietary intake, type 2 diabetes, nutrition therapy, computerised assessment

A ccording to research examining the susceptibility of different occupations to computerisation, dietitians and nutritionists were found to rank 11th for the lowest probability, thus lower than physicians and surgeons (15th) and dentists (19th). ${ }^{(1)}$ Dietitians need to estimate how much energy and nutrients their patients consume, and suggest feasible and realistic menu planning. Such tasks may be more complex than those required from physicians, such as providing a diagnosis according to blood examinations, or dispensing medication, for example.

Medical nutrition therapy is fundamental in the overall diabetes management plan, and education by registered dieticians is effective. ${ }^{(2,3)}$ There is not an effective mix of macronutrients for meal planning that applies broadly to all patients with diabetes, and macronutrient proportions should be individualized. ${ }^{(4,5)}$ To achieve treatment goals, individuals should receive individualised medical nutrition therapy. ${ }^{(5)}$

It has been reported that self-management in terms of diet is a significant predictor of satisfaction and impact of quality of life among people with type 2 diabetes. ${ }^{(6)}$ For feasible, tailored nutrition therapy, by a registered dietitian in only limited consultation time, it is necessary to conduct individual dietary interviews effectively. On this basis, the dietitian can then suggest a simple, bespoke diabetes meal planning approach, such as portion control and healthy food choices.

The objectives of this study were to assess the validity and agreement of dietary computer software in estimating dietary intake in individual Japanese patients with type 2 diabetes.

\section{Methods}

Subjects. We enrolled 46 patients with type 2 diabetes (28 male), from the outpatient clinic at Kyoto Prefectural University of Medicine, Kyoto, Japan. The data were collected from August to November 2015.

Statement of ethics. The experimental protocol was approved by the ethics committees of Kyoto Prefectural University of Medicine (ERB-C-411) and Kyoto Prefectural University, Kyoto, Japan (2015 No. 93). The present study was conducted according to the guidelines laid down in the Declaration of Helsinki.

Dietary computer software. We used the "Syokuseikatsu Shindan System (SSS) ver. 1.2 for Windows 2000/XP" (Nissha, Kyoto, Japan), in collaboration with the Kyoto Dietetic Association. This system is based upon the Dietary Reference Intakes for Japanese (2005) and Health Japan 21. ${ }^{(7)}$ SSS features a function in which the user chooses and clicks pictures of dishes or food displayed on the screen, and chooses the size of the portion he/she consumed (from $1 / 3$ to $9+2 / 3$ times the shown amount) in each meal (breakfast, lunch, dinner, and snacks) over one day. The dishes and foods are categorised into rice, noodles, meats, fish, vegetables, drink, and sweets, which helps patients easily search for items. The patient selects foods and drinks using the 24-h recall method, and if the specific food or drink is not available in the programme, selects the most similar foods or drinks. When patient cannot select dishes or foods, assistance is provided in choosing the most appropriate one. Pictures of each dish are shown using dishes which were strictly cooked on the basis of nutritional calculation. Nutritional values are calculated according to the software programme. The system calculates the nutrient intake on the basis of the weight of food before cooking using the Standard Tables of Food Composition in Japan 2010. ${ }^{(8)}$

Dietary interview by registered dietitians. Soon after estimation of dietary intake using the computer software, regis-

*To whom correspondence should be addressed.

E-mail: poisson@kpu.ac.jp 
tered dietitians in the hospital interviewed patients regarding their meals over one day using the 24 -h recall method. Nutritional value calculations were performed using nutritional calculation software (Excel Eiyo-kun ver. 6.0, Kenpakusha, Tokyo, Japan), and total energy, protein, fat, and carbohydrate intake were determined.

Sample size. We could not conduct a projected sample size calculation due to the absence of suitable data and pilot study findings. Therefore, the sample size was determined by the feasibility of recruitment from August to November 2015.

Statistical analysis. Age (years old), body mass index (BMI, $\left.\mathrm{kg} / \mathrm{m}^{2}\right), \mathrm{HbAlc}(\%)$, total energy intake ( $\mathrm{kcal} /$ day), protein intake (g/day), fat intake (g/day), carbohydrate intake (g/day), protein energy ratio (PER), fat energy ratio (FER), and carbohydrates energy ratio (CER) are presented as means and SD. All data showed a normal distribution according to Shapiro-Wilk normality tests. Nutritional intake for each individual was estimated by both dietitian interview and computer software.

Correlations between the two methods were measured using Pearson's correlation analysis for unadjusted (crude) data. BlandAltman plots ${ }^{(9)}$ were used to assess the agreement between the dietitian interview and the computer software on an individual level. In brief, the mean difference was calculated by subtracting dietitian interview from computer software. The limits of agreement value (LOA) were between (mean difference) $-1.96 \times$ (SD of the mean difference) and (mean difference) $+1.96 \times(\mathrm{SD}$ of the mean difference). A Bland-Altman index of a maximum of $5 \%(95 \%$ of individuals observed to be beyond the limits of agreement; LOA) value was interpreted, as commonly assumed, ${ }^{(10)}$ as a positive validation of the method of measurement. The level of significance was set at $p<0.05$.

All analyses were performed with SPSS Statistics ver. 22.0 (IBM, Chicago, IL).

Table 1. Characteristics and nutritional intakes of patients

\begin{tabular}{lcc}
\hline & Mean \pm SD \\
\hline$n$ (male/female) & $46(28 / 18)$ & \\
Age (years old) & $68.8 \pm 9.6$ & \\
BMI $\left(\mathrm{kg} / \mathrm{m}^{2}\right)$ & $23.3 \pm 3.4$ & \\
HbA1c $(\%)$ & $7.4 \pm 1.0$ & \\
& Interviews & Software \\
Total energy intake (kcal) & $1,639 \pm 431$ & $1,403 \pm 356$ \\
Protein intake (g) & $58.7 \pm 18.6$ & $51.2 \pm 15.4$ \\
Fat intake (g) & $54.5 \pm 24.6$ & $40.2 \pm 17.5$ \\
Carbohydrate intake (g) & $215.5 \pm 52.9$ & $210.6 \pm 55.1$ \\
Protein energy ratio (\%) & $14.5 \pm 3.8$ & $14.7 \pm 2.9$ \\
Fat energy ratio (\%) & $32.5 \pm 18.7$ & $27.5 \pm 13.5$ \\
Carbohydrates energy ratio (\%) & $52.6 \pm 9.6$ & $60.6 \pm 8.1$
\end{tabular}

Values were represented as means \pm SD. Interviews: values were estimated by $24-\mathrm{h}$ dietary recall, Software: values were estimated by computer software.

\section{Results}

Characteristics and nutritional intakes of patients. The average age of patients was $68.8 \pm 9.6$ years old, and obesity (i.e., BMI over $\left.25 \mathrm{~kg} / \mathrm{m}^{2}\right)$ was identified in $15(31.9 \%)$ patients. The average $\mathrm{HbAlc}$ was $7.4 \pm 1.0 \%$. The average total energy intake estimated by dietitian interview and software was 1,639 \pm 431 and $1,403 \pm 356 \mathrm{kcal} /$ day, respectively. PER, FER, and CER which were estimated by dietitian interviews were $14.5 \pm 3.8 \%, 32.5 \pm$ $18.7 \%, 52.6 \pm 9.6 \%$, and those estimated by software were $14.7 \pm$ $2.9 \%, 27.5 \pm 13.5 \%, 60.6 \pm 8.1 \%$, respectively (Table 1 ). The average intake of fat estimated by dietitian interview and the average intake of carbohydrates estimated by software were beyond the recommendation by Dietary Reference Intakes for Japanese ${ }^{(11)}$ but other values were within these recommendations.

Correlation for energy, protein, fat, and carbohydrate intake between dietitian interview and computer software methods. The crude correlation coefficients between dietitian interview and the computer software for energy ( $\mathrm{kcal} /$ day), protein (g/day), fat (g/day), and carbohydrate (g/day) intake were 0.71 , $0.63,0.67$, and 0.53 , respectively, and all correlation coefficients were statistically significant (Table 2). Although there was one outlier, in which fat intake was estimated to be $133.6 \mathrm{~g} /$ day by dietitian interview, this data was also included the analyses.

Assessment of agreement between dietitian interview and computer software methods on energy, protein, fat and carbohydrate intakes. Bland-Altman analysis was used to assess agreement between two methods. More than $95 \%$ of fat and carbohydrate intakes were within LOA, however only $93.5 \%$ was within LOA for energy intake and $91.3 \%$ was within LOA for protein (Table 3 ). For energy, the mean difference (bias) between dietitian interview and computer software was $-236 \mathrm{kcal}$ and the $95 \%$ limits of agreement ranged from -854 to $382 \mathrm{kcal}$. The assessed bias for protein, fat, and carbohydrate was $-7.5 \mathrm{~g},-14.3 \mathrm{~g}$, and -5.0 g, respectively (Table 3 , Fig. 1), and it was found that these were underestimated by the computer software compared to dietitian interview.

\section{Discussion}

This study assessed the validity and agreement of nutritional intake estimation by computer software compared with dietitian interview in Japanese type 2 diabetes patients.

Table 2. Peason's correlation coefficients for energy, protein, fat and carbohydrate intake between dietitian interview and the computer software

\begin{tabular}{lcc}
\hline & $r$ & $p$ value \\
\hline Total energy intake $(\mathrm{kcal})$ & 0.708 & $<0.001$ \\
Protein intake $(\mathrm{g})$ & 0.629 & $<0.001$ \\
Fat intake $(\mathrm{g})$ & 0.666 & $<0.001$ \\
Carbohydrate intake $(\mathrm{g})$ & 0.532 & $<0.001$ \\
\hline
\end{tabular}

All nutrients data are based on crude intakes. $n=46$, by Pearson's correlation analyses.

Table 3. Bland-Altman analysis for energy and nutritions by 1 day of computer software and the dietitian interviews

\begin{tabular}{lcccc}
\hline & Bias & Precision & LOA & Within LOA (\%) \\
\hline Total energy intake $(\mathrm{kcal})$ & -236 & 309 & $-842-369$ & 93.5 \\
Protein intake $(\mathrm{g})$ & -7.5 & 14.9 & $-36.8-21.8$ & 91.3 \\
Fat intake $(\mathrm{g})$ & -14.3 & 18.2 & $-50.4-21.7$ & 97.8 \\
Carbohydrate intake $(\mathrm{g})$ & -5.0 & 52.3 & $-107.4-97.5$ & 97.8 \\
\hline
\end{tabular}

LOA, limits of agreement. 
Table 4. Comparison of bias and precision between this study and previous studies

\begin{tabular}{|c|c|c|c|c|c|c|}
\hline & \multicolumn{3}{|c|}{ Bias } & \multicolumn{3}{|c|}{ Precision } \\
\hline & This study & Rangan $^{(20)}$ & Carter $^{(21)}$ & This study & Rangan $^{(20)}$ & Carter $(21)$ \\
\hline Total energy intake (kcal) & -236 & -8 & 16 & 309 & 498 & 402 \\
\hline Protein intake $(\mathrm{g})$ & -7.5 & -2.5 & -2 & 14.9 & 22.5 & 18 \\
\hline Fat intake $(\mathrm{g})$ & -14.3 & -1.4 & -3 & 18.2 & 23.5 & 26 \\
\hline Carbohydrate intake (g) & -5.0 & 4.3 & -5 & 52.3 & 70.1 & 62 \\
\hline
\end{tabular}
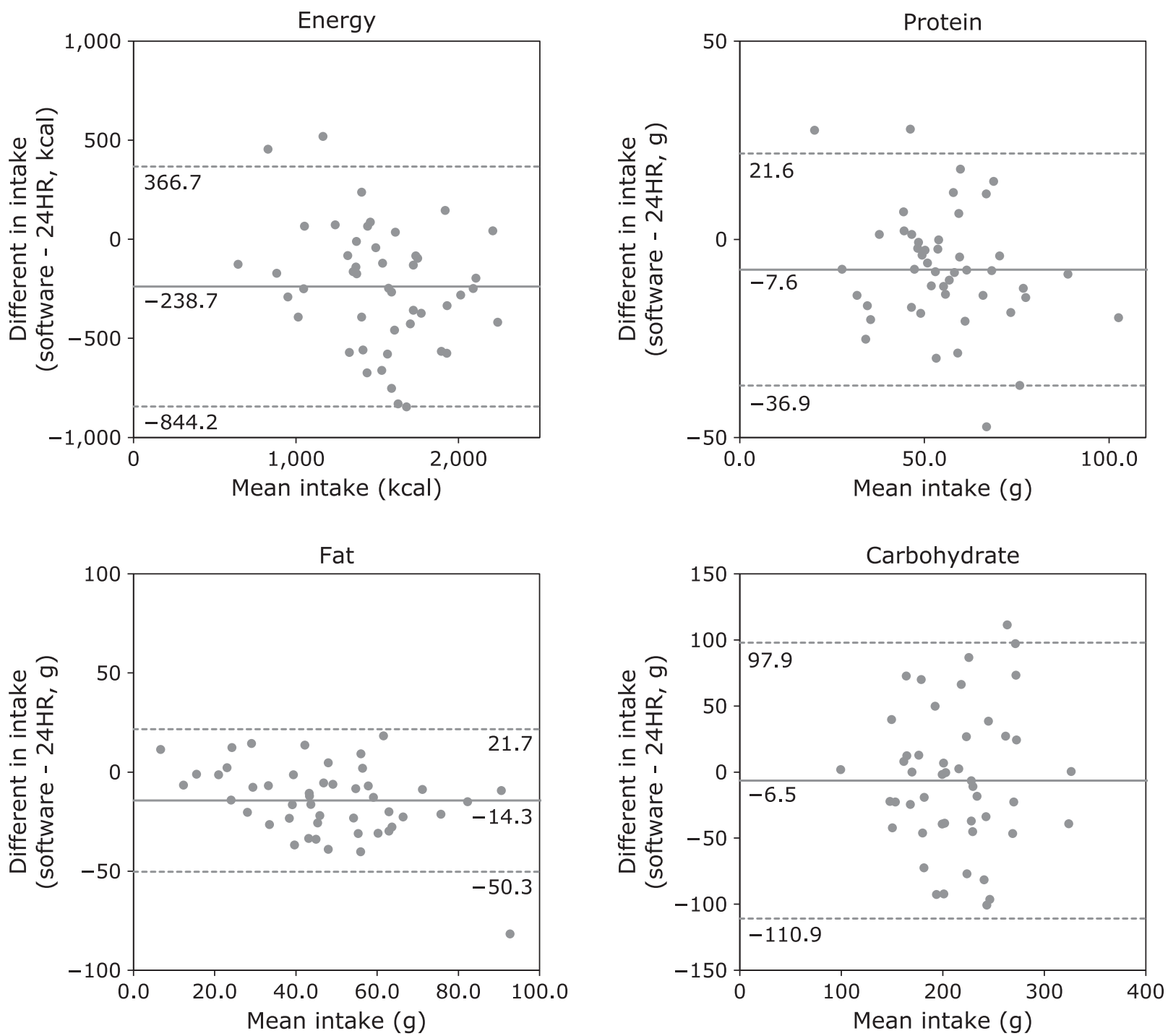

Fig. 1. Bland-Altman plot of 24-h dietary recall (24HR) and computer software for energy, protein, fat, and carbohydrate intake. Differences in intake between methods are plotted against the mean of the two methods. The solid line indicates the bias (mean difference), and the dashed lines indicate the $95 \%$ limits of agreement $(1.96 \times$ SD).

In a previous study of type 2 diabetes in Australia using mobile phone image-based dietary assessment compared with weighed food records, the Pearson's correlations for energy, protein, fat, and carbohydrates were $0.57,0.78,0.24$, and 0.63 , respectively. ${ }^{(12)}$ Our results showed better correlations for energy and fat, but lower correlations for protein and carbohydrates. The difference in dietary habits between countries might be partially responsible for these findings; for example, a dietary staple in Australia is bread, which is easier to estimate in terms of intake, while in Japan it is rice. Other studies have found the validation of dietary estimation of carbohydrates correlations to be 0.40 to 0.65 in Japan, ${ }^{(13-15)}$ and 0.32 to 0.62 in other countries. ${ }^{(16-19)}$ Our study found a stronger correlation for carbohydrates than these previous studies.

We developed this dietary computer software with the aim of shortening the length of dietitian interviews for intake estimation. Therefore, validation on an individual basis is more important than validation for the group, and so we assessed the individual agreement between the dietitian interview and the computer software. 
In previous research assessing the validation of nutritional intake by computerised devices compared with 24-h dietary recall, Rangan and colleagues ${ }^{(20)}$ found that the mean difference in energy, protein, fat, and carbohydrate intake was $-8.2 \mathrm{kcal}(-34.3 \mathrm{~kJ})$, $-2.5 \mathrm{~g},-1.4 \mathrm{~g}$, and $4.3 \mathrm{~g}$, respectively, whereas Carter et al. ${ }^{(21)}$ report mean differences of $-16 \mathrm{kcal},-2 \mathrm{~g},-3 \mathrm{~g}$, and $-5 \mathrm{~g}$, respectively (Table 4). Our data show higher mean differences than these previous papers. Nutritional intake was underestimated by computer software, potentially because older type 2 diabetes patients participated in this study, compared to potentially younger healthy subjects were recruited in previous studies. The SD of mean difference in our study, Rangan's study, ${ }^{(20)}$ and Carter's study ${ }^{(21)}$ were $309 \mathrm{kcal}, 499 \mathrm{kcal}$, and $404 \mathrm{kcal}$ in energy, respectively; $14.9 \mathrm{~g}, 22.5 \mathrm{~g}$, and $18 \mathrm{~g}$ in protein, respectively; $18.2 \mathrm{~g}, 23.5 \mathrm{~g}$, and $16 \mathrm{~g}$ in fat, respectively; and $52.3 \mathrm{~g}, 70.1 \mathrm{~g}$, and $62 \mathrm{~g}$ in carbohydrate, respectively (Table 4). Although the SD in our study are similar to previous studies, these are nonetheless quite wide for clinical use.

Several papers assessing nutritional intake by computerised devices compared with dietary records showed better mean difference and LOA than our study. ${ }^{(22-24)}$ In these studies, subjects were younger (mean ages were 21.4 to 39.3 years) than in our study (mean age of 68.8 years), and computerised dietary records were recorded by smartphone, internet, and photographs taken of meals before eating. Previous methods of nutritional estimation are more accurate but may not be feasible for use by older type 2 diabetes patients, since the patients in our study hardly used these technological tools. Although our method was found to be less accurate, patients are able to select dish-based meals using the 24-h recall method with support by medical stuff when a patient has a difficulty to deal with, which we believe to be more feasible. Using this approach, dietitians may be able to correct nutritional estimation in their interview, for example using a food model for identifying accurate portions. It takes approximately $10 \mathrm{~min}$ to input dietary information for one day using our computerised programme. When patients input information during their waiting time in the hospital or clinic before the dietitian consultation, dietitians are able to reduce the time required for the diet interview, then spend more time on individualised dietary education. In Japan, more than $20 \mathrm{~min}$ per consultation is necessary to receive the nutritional dietary advice fee according to the Medical fee revision 2018. ${ }^{(25)}$ This computer software might shorten the

\section{References}

1 Frey CB, Osborne MA. The future of employment: how susceptible are jobs to computerisation? Technological Forecasting and Social Change 2017; 114: $254-280$.

2 Evert AB, Dennison M, Gardner CD, et al. Nutrition therapy for adults with diabetes or prediabetes: a consensus report. Diabetes Care 2019; 42: 731754.

3 Haneda M, Noda M, Origasa H, et al. Japanese Clinical Practice Guideline for Diabetes 2016. Diabetol Int 2018; 9: 1-45.

4 American Diabetes Association. Standards of medical care in diabetes2013. Diabetes Care 2013; 36 Suppl 1: S11-S66.

5 Evert AB, Boucher JL, Cypress M, et al. Nutrition therapy recommendations for the management of adults with diabetes. Diabetes Care 2013; 36: 38213842

6 Kueh YC, Morris T, Borkoles E, Shee H. Modelling of diabetes knowledge, attitudes, self-management, and quality of life: a cross-sectional study with an Australian sample. Health Qual Life Outcomes 2015; 13: 129.

7 Ministry of Health, Labour and Welfare, Japan. Dietary Reference Intakes for Japanese (2005). http://www.nibiohn.go.jp/en/files/Section_of_the_Dietary_ Reference_Intakes/dris2005_eng.pdf. Accessed 13 Mar 2020.

8 Watanabe T. Food composition tables of Japan and the nutrient table/ database. J Nutr Sci Vitaminol (Tokyo) 2015; 61 Suppl: S25-S27.

9 Bland JM, Altman DG. Statistical methods for assessing agreement between two methods of clinical measurement. Lancet 1986; 1: 307-310.

10 Głąbska D, Guzek D, Sidor P, Włodarek D. Vitamin D dietary intake duration of dietary estimation by dietitians and allow them more time to advise how patients can change their eating behaviours during this limited consultation time.

There are some limitations of the current study. First, the sample size was small (46 patients); however, it is still within the range of sample sizes reported in similar studies, that is, between 45 to 163 subjects. ${ }^{(12,20-24)}$ Second, the subjects were all outpatients in a university hospital, and thus might not represent the presentation of typical Japanese type 2 diabetes. Third, we validated only total energy intake and macronutrients (protein, fat, and carbohydrate), but not the other nutrients which are beneficial ${ }^{(26)}$ or unfavorable $^{(27)}$ for type 2 diabetes.

In conclusion, this system is manageable and useable by older patients. The nutritional estimation using our computer software correlated well with the dietitian interviews indicating this is a valid measure of nutrition intake. Although LOA was broad, the software can reduce the duration of dietitian interviews, and estimated data from the software can be made available for clinical use with support from dietitians.

\section{Author Contributions}

Research questions were formulated by: SW and YK; study design was generated by: MF, MH, and $\mathrm{SW}$; the study was conducted by: EY, MOtsuki, CT, WA, MOkagaki, HN, MT, and $\mathrm{AH}$; analysis of the data and article write-up were completed by: SW. All authors read and approved the final manuscript.

\section{Acknowledgments}

The authors wish to acknowledge Kazuko Tamagawa, previous president of the Kyoto Dietetic Association and editorial supervisor of SSS for her help in interpreting the results of this study.

\section{Financial Support}

This work was supported by KPUM-KPU Collaborative Research Program 2015 to SW.

\section{Conflict of Interest}

No potential conflicts of interest were disclosed.

questionnaire validation conducted among young polish women. Nutrients 2016; 8: 36 .

11 Ministry of Health, Labour and Welfare. Overview of Dietary Reference Intakes for Japanese 2015. https:/www.mhlw.go.jp/file/06-Seisakujouhou10900000-Kenkoukyoku/Overview.pdf (in Japanese). Accessed 9 Apr 2020.

12 Rollo ME, Ash S, Lyons-Wall P, Russell AW. Evaluation of a mobile phone image-based dietary assessment method in adults with type 2 diabetes. Nutrients 2015; 7: 4897-4910.

13 Egami I, Wakai K, Kato K, et al. A simple food frequency questionnaire for Japanese diet -- Part II. Reproducibility and validity for nutrient intakes. $J$ Epidemiol 1999; 9: 227-234.

14 Ishihara J, Inoue M, Kobayashi M, et al. Impact of the revision of a nutrient database on the validity of a self-administered food frequency questionnaire (FFQ). J Epidemiol 2006; 16: 107-116.

15 Tsubono Y, Ogawa K, Watanabe Y, et al. Food frequency questionnaire and a screening test. Nutr Cancer 2001; 39: 78-84.

16 Boucher B, Cotterchio M, Kreiger N, Nadalin V, Block T, Block G. Validity and reliability of the Block98 food-frequency questionnaire in a sample of Canadian women. Public Health Nutr 2006; 9: 84-93.

17 Shatenstein B, Nadon S, Godin C, Ferland G. Development and validation of a food frequency questionnaire. Can J Diet Pract Res 2005; 66: 67-75.

18 Subar AF, Thompson FE, Kipnis V, et al. Comparative validation of the Block, Willett, and National Cancer Institute food frequency questionnaires: the Eating at America's Table Study. Am J Epidemiol 2001; 154: 1089-1099. 
19 Toft U, Kristoffersen L, Ladelund S, et al. Relative validity of a food frequency questionnaire used in the Inter99 study. Eur J Clin Nutr 2008; 62: 1038-1046.

20 Rangan AM, O'Connor S, Giannelli V, et al. Electronic dietary intake assessment (e-DIA): comparison of a mobile phone digital entry app for dietary data collection with 24-hour dietary recalls. JMIR Mhealth Uhealth 2015; 3: e98.

21 Carter MC, Burley VJ, Nykjaer C, Cade JE. 'My Meal Mate' (MMM): validation of the diet measures captured on a smartphone application to facilitate weight loss. Br J Nutr 2013; 109: 539-546.

22 Matsuzaki E, Michie M, Kawabata T. Validity of nutrient intakes derived from an internet website dish-based dietary record for self-management of weight among Japanese women. Nutrients 2017; 9: 1058.

23 Kong K, Zhang L, Huang L, Tao Y. Validity and practicability of smartphonebased photographic food records for estimating energy and nutrient intake. Asia Pac J Clin Nutr 2017; 26: 396-401.

24 Lazarte CE, Encinas ME, Alegre C, Glanfeldt Y. Validation of digital photographs, as a tool in 24-h recall, for the improvement of dietary assessment among rural populations in developing countries. Nutr J 2012; 11: 61.

25 The Japan Dietetic Association. Shinryohoushu ni tsuite. https://www. dietitian.or.jp/data/medical-fee/ (in Japanese). Accessed 13 Mar 2020.

26 Hua L, Lei M, Xue S, Li X, Li S, Xie Q. Effect of fish oil supplementation combined with high-intensity interval training in newly diagnosed non-obese type 2 diabetes: a randomized controlled trial. J Clin Biochem Nutr 2020; 66: 146-151.

27 Ushigome E, Oyabu C, Iwai K, et al. Effects of dietary salt restriction on home blood pressure in diabetic patients with excessive salt intake: a pilot study. J Clin Biochem Nutr 2019; 65: 252-257.

This is an open access article distributed under the terms of the Creative Commons Attribution-NonCommercial-NoDerivatives License (http://creativecommons.org/licenses/by-nc-nd/4.0/). 